\title{
REFLEXÕES E PERCEPÇÕES SOBRE A MOBILIDADE E UBIQUIDADE DAS TECNOLOGIAS DIGITAIS EM UM CONTEXTO CAÓTICO
}

\section{REFLECTIONS AND PERCPETIONS ON MOBILITY AND UBIQUITY OF DIGITAL TECHNOLOGIES IN CHAOTIC CONTEXT}

\author{
Victor Ferreira Ragoni ${ }^{1}$
}

\begin{abstract}
Resumo: Diante do atual contexto em que o mundo se encontra, de caos, de isolamento social e de relações pessoais modificadas abruptamente, a educação foi alterada praticamente de um dia para o outro. O objetivo deste trabalho é refletir sobre as possibilidades que as tecnologias digitais móveis trazem para a educação em tempos de pandemia e isolamento. Assim, as tecnologias podem influenciar diretamente no cenário educacional, minimizando efeitos da pandemia para que a educação não pare completamente, para que alunos não fiquem um ano sem escolarização e para que não haja atrasos em calendários. Novos desafios são postos: professores precisam informar-se e formar-se nas tecnologias digitais móveis, alunos precisam se adaptar aos novos estilos de aprendizagem, assim como pais e responsáveis agora possuem mais encargos na educação dos filhos. Todas as esferas da sociedade foram afetadas, no entanto é preciso que tiremos algo disso tudo: novas possibilidades de interação, ensino e aprendizagem.
\end{abstract}

Palavras-chave: Ensino Remoto; Tecnologias; Pandemia; Educação.

Abstract: Given the current context in which the world finds itself, in a chaos, social isolation and personal relationships abruptly modified in an education was practically changed overnight. The objective of this work is to reflect on the possibilities that digital mobile technologies bring to education in times of pandemic and isolation. Thus, as technologies can directly influence the educational scenario, minimizing pandemic effects so that education does not stop completely, so that students do not go a year without schooling and so that there are no delays in calendars. New challenges are posed: teachers need to be informed and educated about mobile digital technologies, students need to adapt to new learning styles, parents and guardians now have more responsibilities in raising their children. All spheres of society were affected, but we need to get something out of it all: new possibilities for interaction, teaching and learning.

Keywords: Remote Teaching; Technologies; Pandemic; Education.

\section{Introdução}

Observando o contexto pandêmico no qual se encontra o mundo no ano de 2020, algumas perguntas surgem quando estamos imersos em uma realidade diferente. Tudo isso faz com que pensemos sobre a possibilidade de nos importarmos com o outro.

Nessa cultura modificada, indago-me sobre a capacidade humana de se emocionar com e por outros seres. Nós, humanos, movemos-nos em direção à razão e esquecemos de aceitar o outro como legítimo outro. Para que isso seja mudado, uma

\footnotetext{
${ }^{1}$ Mestrando no Programa de Pós-Gradução em Educação Matemática, Universidade Federal de Mato Grosso do Sul (UFMS), Campo Grande, Mato Grosso do Sul, Brasil. E-mail: ragonivictor@ hotmail.com.
} 
DOI: https://doi.org/10.33238/ReBECEM.2020.v.4.n.3.24856

pandemia, ou seja, um contexto atípico, pode ser um fator necessário a fim de que o pano causador da cegueira da valorização da razão seja exposto.

Refletir sobre razão e emoção faz com que sigamos em direção a questões atreladas ao campo de educação como, por exemplo: Por que é tão importante ter o contato social e pessoal com meus alunos para o ensino e aprendizagem? Como possibilitar o ensino e a aprendizagem para os meus alunos, os quais estão tão acostumados com a sala de aula presencial a partir do isolamento social? Como buscar novas formas de ensinar e proporcionar a aprendizagem a distância em um contexto de pandemia?

Para discorrer sobre tais perguntas, reflito neste ensaio sobre as Tecnologias Digitais Móveis (TDM), a fim de proporcionar uma reflexão e uma ponderação quanto ao uso destas ferramentas. Entendo que um ensaio seja um possível modo de trazer considerações sobre a realidade atual pela qual não somente o Brasil, mas também todo o resto do mundo, está passando, uma vez que é necessário certa urgência e cautela ao tratar destas temáticas.

Nesse sentido, evidenciei nesta introdução uma pequena consideração sobre o que entendo pelo termo "ensaio teórico". Logo, para chegar a uma definição, corroboro Meneghetti (2011, p. 323), “o ensaio é um meio de análise e elucubrações em relação ao objeto, independentemente de sua natureza ou característica [...]”. O autor ainda explica que é preciso originalidade, subjetividade e maturidade por parte do ensaísta (MENEGHETTI, 2011).

O ensaio ainda possui algumas características tais como sua natureza reflexiva e interpretativa, valorização de aspectos qualitativos, meio para compreensão da realidade, e "[...] busca-se a construção da forma adequada, mesmo que esta não exista a princípio. Nele, o objeto exerce primazia, mas a subjetividade do ensaísta está permanentemente em interação [...]” (MENEGHETTI, 2011, p. 323).

Além das perguntas já mencionadas anteriormente, algumas outras questões são levantadas, podendo servir de norte para o desenrolar desse ensaio, as quais menciono: Como as TDMs podem influenciar a educação em cenários caóticos? Quais possibilidades são proporcionadas pelas TDMs nesse cenário? Necessita-se refletir sobre como essas tecnologias proporcionam à educação um caminhar no contexto vivenciado, mesmo que devagar. É, portanto, pertinente expor funcionalidades e possibilidades desses artefatos para o auxílio em tempos incertos. 
DOI: https://doi.org/10.33238/ReBECEM.2020.v.4.n.3.24856

Com tais perguntas, procuro explorar as TDMs - mas não esgotar o assunto com o objetivo de proporcionar estudos e análises que possibilitem aos educadores refletir sobre seus processos educativos. A partir disso, elaboro como principal objetivo para esse trabalho a reflexão quanto às possibilidades que as tecnologias digitais móveis trazem para a educação em tempos de pandemia e isolamento.

No desenrolar dessa análise, buscarei explorar o cenário emergente que nos encontramos, no qual vidas foram afetadas e mudadas radicalmente quase que do dia para a noite, com políticas públicas de combate a um vírus (SARS-CoV-2) que trouxe caos ao mundo, ocasionando a pandemia do coronavírus.

Apresento em seguida considerações sobre as TDMs, com reflexões de autores que ponderam sobre algumas características como a mobilidade, a ubiquidade e, como a sala de aula e os hábitos podem ser transformados. Ademais, debato também sobre o ensino remoto, que foi uma possibilidade apresentada à educação, como potencial para o ensino e aprendizagem em contextos como o atual.

Entrelaçando esses dois temas, ensino remoto e TDMs, faço por fim uma seção onde discorro sobre o que as TDMs podem trazer de ajuda aos professores, alunos e toda a cultura educacional. Algumas implicações sobre a prática do ensino e a prática dos alunos também são tratadas nessa seção. Finalizando, tento fazer reflexões, mesmo incertas, do futuro da educação com tantas mudanças ocorridas em menos de um semestre do ano de 2020, de como essas mudanças podem alterar as relações entre pessoas bem como entre indivíduos e a tecnologia.

\section{0 cenário emergente}

Atualmente nos encontramos imersos em uma realidade totalmente diferente daquela com a qual estávamos habituados. Nossas rotinas se alteraram, nossas vidas foram afetadas e transformadas. Estamos cerceados por um vírus que nos provoca uma pandemia. O medo está presente a todo instante, o cenário que se apresenta aparenta ser apocalíptico, mas é necessário que todos tenhamos calma. Estamos reaprendendo a ser humanos. Encontramo-nos repensando atividades diárias, como ir ao supermercado e fazer compras. Regras são impostas para conter o avanço do vírus, chamado cientificamente por SARS-CoV-2 e que ficou conhecido como coronavírus, em nossa sociedade. As escolas e universidades pararam, e a recomendação consiste em 
DOI: https://doi.org/10.33238/ReBECEM.2020.v.4.n.3.24856

isolamento social e cuidados adicionais com higiene, uso de máscaras e distanciamento social aos que precisam transitar (BRASIL, 2020).

Neste momento, a sociedade reinventa-se, modifica-se, reestrutura-se, reencontra-se. Um vírus, causador de mortes em escalas alarmantes, fez todo o mundo, - e dizemos isso aqui com base nos diferentes países existentes - readaptar suas rotinas. Através do ato de readaptar-se, de reinventar-se, é perceptível também que os espaços educativos (escolas, universidades, cursos profissionalizantes, etc.) tiveram de modificar suas estruturas ou mesmo paralisar as aulas como, por exemplo, os decretos estaduais No 40.520, DE 14 de março de 2020 do governo do Distrito Federal e No 64.862, de 13 de março de 2020 do governo do estado de São Paulo²

Trago aqui, portanto, um termo que, ao ler, pode-se ter certa noção sobre seu significado, enunciado como pandemia, ainda que muitas vezes seja confundido com outras palavras, como epidemia e endemia. Em termos numéricos, uma pandemia é como se fosse uma epidemia que atinge uma maior quantidade de casos (REZENDE, 1998). A pandemia atual trouxe novos cenários como, por exemplo, o distanciamento entre pessoas e os diferentes modos de se cumprimentar. Desta forma, para se enfrentar a doença, uma das regras impostas para a sociedade é o isolamento social que obriga muitas pessoas a ficarem trancadas em casa.

Não é difícil de confundir os termos acima comentados. Para caracterizar uma epidemia, Rezende (1998, p. 153) comenta que é “[...] o elevado número de casos novos e sua rápida difusão [...]" que define o termo, ou seja, basta o caráter quantitativo. Para determinar o termo pandemia, o autor utiliza-se da definição de epidemia, ou seja, "o conceito moderno de pandemia é o de uma epidemia de grandes proporções, que se espalha por vários países e a mais de um continente" (REZENDE, 1998, p. 154).

$\mathrm{O}$ isolamento social, segundo autoridades médicas, é um dos métodos mais eficazes de prevenção e diminuição da difusão do vírus entre as pessoas. Alguns países que demoraram a entender que esse era um meio a seguir tiveram numerosas mortes, como é o caso da Itália, cujas autoridades aparentemente demoraram a reconhecer essa necessidade. Com isso, "as autoridades italianas tentaram retomar uma política de quarentena e isolamento em 09 de março, quando o número de mortos chegou a 463 [...]” (EL PAÍS, 2020), dado que o país apresentava 34 mortes no dia $1^{\circ}$ de março, um

\footnotetext{
${ }^{2}$ Trago apenas dois decretos, pois a continuação ou paralisação das aulas é responsabilidade dos governos estaduais.
} 
DOI: https://doi.org/10.33238/ReBECEM.2020.v.4.n.3.24856

aumento de 424 casos em oito dias e média de 53 casos diariamente. Mais tarde a Itália passaria a ser o epicentro da pandemia na Europa.

$\mathrm{O}$ vírus SARS-CoV-2 tem uma taxa de contaminação, a depender das medidas de prevenção, muito alta, ou seja, a partir de apertos de mão, gotículas de saliva que são expelidas a partir da fala, espirros, tosse, catarro e objetos e superfícies já contaminadas (BRASIL, 2020).

Este vírus sendo um patógeno da família dos gripais, sendo sua principal consequência a infecção respiratória. $\mathrm{O}$ vírus começou a ser investigado após alguns casos da doença, a qual é intitulada de COVID-19, serem registrados na China. Nesse país, a quantidade de mortos chegou a 4.641, segundo o site da Universidade Johns Hopkins, enquanto no Brasil o número de casos fatais chegou a 60.632 até o dia 01 de julho de 2020. Em termos mundiais, esse número chega a 516.646 até a mesma data.

Os principais sintomas da COVID-19 são: tosse, febre, coriza, dor de garganta e dificuldade para respirar; este último sendo um sintoma fundamental para que o caso seja considerado suspeito e investigado com mais afinco (BRASIL, 2020) ${ }^{3}$. Há ainda uma variação da doença de resfriados a pneumonia severa, dependendo de outros fatores como imunidade e presença ou não de comorbidades que influenciam na sua gravidade, como salienta Baptista e Fernandes (2020). Segundo os autores, "casos graves da COVID-19 têm sido associados a doenças crônicas como cardiovasculares, principalmente hipertensão, diabetes, neoplasias e doenças respiratórias" (BAPTISTA; FERNANDES, 2020, p. 40).

Por ser considerado de fácil disseminação, o vírus começou a alarmar muitas esferas da sociedade desde o fim do ano de 2019, causando pânico, afetando economias, trazendo caos aos sistemas de saúde e de cemitérios, provocando o que Conti (2020) enuncia como "crise sanitária". Foram necessárias diversas medidas de controle como a quarentena e o isolamento social, acabando por afetar também as salas de aula, o que gera um movimento de readaptação dos espaços e processos educacionais. Uma dessas alternativas é o uso de tecnologias digitais móveis.

\footnotetext{
${ }^{3}$ Sobre a doença e os sintomas podem ser encontradas maiores informações no site do Ministério da Saúde. Disponível em: <https://coronavirus.saude.gov.br/sobre-a-doenca>. Acesso em: 23 de julho de 2020 .
} 
DOI: https://doi.org/10.33238/ReBECEM.2020.v.4.n.3.24856

\title{
3 Tecnologias digitais móveis, mobilidade e ubiquidade
}

Para tentar não ser ainda mais afetado pelo panorama da pandemia, e fazer com que os espaços educativos não sejam prejudicados, as aulas estão sendo diariamente repensadas, modificadas e adaptadas para a modalidade de ensino remoto, contando com o auxílio de outras tecnologias que possuem na mobilidade e na ubiquidade suas principais características. Essas duas peculiaridades são conceitos já em discussão por pesquisadores, como Santaella $(2010 ; 2013)$ e podem implicar em uma nova configuração de educação, tanto no auxílio da realidade vivida em 2020 quanto em possibilidades futuras. Tais termos, mobilidade e ubiquidade, entram em debate quando se pensa em uma educação que deve priorizar o distanciamento entre os pares. A partir disso, analisa-se também a educação dentro dessa era tecnológica, na qual a mobilidade e o instantâneo exigem mais ainda do professor e do aluno. Nas palavras de Santaella (2013, p. 276),

\begin{abstract}
Antes dos equipamentos móveis, nossa conexão às redes dependia de uma interface fixa, os computadores de mesa. Enquanto as redes digitais, por sua própria natureza, são sempre móveis, a entrada das nas redes implicava que o usuário estivesse parado a frente do ponto fixo do computador. Agora, ao carregar consigo um dispositivo móvel, a mobilidade se torna dupla: mobilidade informacional e mobilidade física do usuário. Para navegar de um ponto a outro das redes informacionais, nas quais se entra e se sai para múltiplos destinos [...]. O acesso passa a se dar em qualquer momento e em qualquer lugar $[\ldots]$
\end{abstract}

Discutir o termo mobilidade é falar do que pode se movimentar, algo móvel, etc. A partir do advento dos dispositivos móveis, a conexão às redes de internet tornou-se ainda mais fácil do ponto de vista material. Com a mobilidade, tornou-se possível andar com seu computador pessoal na bolsa. Assim, “[...] à mobilidade física do cidadão cosmopolita foi acrescida a mobilidade virtual das redes. Ambas as mobilidades entrelaçaram-se, interconectaram-se e tornaram-se mais agudas pelas ações de uma sobre a outra [...]" (SANTAELLA, 2013, p. 277).

É, assim, nesse entrelaçar de mobilidades que surge o novo perfil de leitor, chamado de "leitor ubíquo" pela autora, e que nos encaminha a conversar sobre o outro termo: ubiquidade. Quando se trata de ubiquidade tecnológica, fala-se de uma "[...] coordenação de dispositivos inteligentes, móveis e estacionários para prover aos usuários acesso imediato e universal à informação e novos serviços, de forma transparente, visando aumentar as capacidades humanas [...]" (SANTAELLA, 2013, p. 16-17). 
DOI: https://doi.org/10.33238/ReBECEM.2020.v.4.n.3.24856

A autora ainda comenta que ubiquidade não é o mesmo que mobilidade, mas que este conceito é caracterizado pelo compartilhamento de vários lugares ao mesmo tempo (SANTAELLA, 2010). A partir disso, tem-se a potencialização das tecnologias digitais móveis com a internet transformando os espaços de casa em sala de aula. Uma TDM, que é amplamente utilizada para passatempo e comunicação, como o smartphone, pode ser hoje pensada para a educação após as suas décadas de evolução, quando saiu do lugar de um simples dispositivo comunicativo de dimensões grandes para um "computador de mão".

[...] por meio deles, à continuidade do tempo se soma a continuidade do espaço: a informação é acessível de qualquer lugar. Os artefatos móveis evoluíram nessa direção tornando absolutamente ubíquos e pervasivos o acesso à informação, a comunicação e a aquisição de conhecimento (SANTAELLA, 2013, p. 291).

A verdade é que as tecnologias como um todo podem trazer novas possibilidades para o ensino e aprendizagem remotos. Interatividade, tarefas de casa, vídeos como artefato de ensino, entre outras possibilidades que as tecnologias proporcionam, são trazidas para esse novo contexto de uma educação no qual as pessoas estão distantes.

Vejo que, a partir da pandemia do coronavírus em 2020, a mobilidade das tecnologias digitais aliada à ubiquidade elabora novos modos de se aprender, de ensinar, de pensar a educação. Com este "novo normal", foi necessário que o professor aprendesse a utilizar-se e adaptar-se a usar as TDMs. Sendo assim, a ubiquidade trouxe o caráter de ensinar em qualquer lugar.

Kenski (2012) ainda comenta que as mudanças nas estruturas da aula não são fáceis, ou seja, "nas salas de aula tradicionais, as pessoas se veem, tocam-se. Sorriem e comunicam-se pelas linguagens do corpo [...]” (KENSKI, 2012, p. 66). Entretanto, neste novo contexto, isso não é possível.

Borba, Scucuglia e Gadanidis (2015, p. 78) comentam que os smartphones para o ensino e aprendizagem " [...] assumem diferentes tendências nas perspectivas nacionais e internacionais, principalmente com relação à educação a distância ou semipresencial [...]”. Ainda é preciso ponderar, contudo, que esse bem de consumo tem se popularizado entre os alunos, mesmo com as desigualdades entre os dispositivos existirem. É possível, portanto, que essas TDMs façam parte das aulas por contar com aplicativos variados, embora essa discussão sobre o uso, local de uso e suas 
DOI: https://doi.org/10.33238/ReBECEM.2020.v.4.n.3.24856

possibilidades ainda esteja em constante transformação (BORBA; SCUCUGLIA; GADANIDIS, 2015).

Além disso, o que se vive em 2020 não é a educação a distância (EaD), mas o ensino remoto. É importante lembrar que se trata de modos de ensinar diferentes. Enquanto a EaD se configura por ter uma estrutura toda estudada para essa modalidade, a pandemia gerou a " $[\ldots]$ obrigatoriedade dos professores e estudantes migrarem para a realidade online, transferindo e transpondo metodologias e práticas pedagógicas típicas dos territórios físicos de aprendizagem naquilo que tem sido designado por ensino remoto [...]" (MOREIRA; HENRIQUES; BARROS, 2020, p. 352, grifo dos autores). Ou seja, o que aconteceu foi a mudança de um estado de aula física levando o que já se utilizava anteriormente para o ambiente online.

É preciso ainda pensar em vários âmbitos com focos diversificados, além de refletir sobre cada um deles. Um desses âmbitos é a formação de professores inseridos no contexto educacional. Tais professores não possuem ou não passaram por uma formação que privilegia as tecnologias para o desenvolvimento de atividades, ou seja, ainda falta formação docente para o uso pedagógico desses artefatos (FIGUEIREDO; RODRIGUES, 2020).

Alguns professores se indagaram "como darei aquela aula para os alunos sem ter uma reunião presencial?". Nesse cenário assustador de pandemia, entram em cena as tecnologias digitais, e estes mesmos professores precisaram formar-se individualmente e informar-se rapidamente, visto que contextos educacionais presenciais não foram pensados para o ensino a distância. Os docentes não foram formados para usar o computador, o vídeo, a câmera e outras tecnologias para o ensino. Um novo desafio se desenhou para docentes: apropriar-se dessas TDMs para ter a possibilidade de educar em tempos complexos.

Assim é possível notar que, no tocante ao ensino e aprendizagem,

[...] estudantes, professores e tutores sabem e utilizam tecnologias digitais em situações rotineiras como compras online, transações bancárias, envio de mensagem e fotos pessoais, etc. No entanto, têm dificuldade para relacionar a possibilidade de utilização dessas mesmas tecnologias [...] (CHIARI, 2018, p. 1273).

Agora iniciarei uma discussão de como há o entrelaçamento entre as TDMs e o atual cenário, embora isso já tenha sido brevemente exposto nos parágrafos anteriores. 


\section{Como isso se entrelaça?}

DOI: https://doi.org/10.33238/ReBECEM.2020.v.4.n.3.24856

Enquanto os professores pensavam suas aulas com o giz, lousa, lápis e papel, agora é preciso pensar em como modificar tudo isso para um cenário onde não se tem proximidade física, nem mesmo lousa e giz para explicação. A questão da ubiquidade, de estar em vários lugares, encaixa-se totalmente nesse novo cenário. O professor precisa estar em sua própria casa pensando as aulas para os alunos que estão na casa deles, ainda que ambos acessem um ambiente para ensinar e aprender.

É possível dizer que o ensino remoto foi imposto sem reflexões sobre o que isso poderia ocasionar, pensando ceticamente a relação do professor com as tecnologias. Em outras palavras, pode-se dizer que é a educação a distância que proporciona a mínima condição de continuar o processo de ensino e aprendizagem que até então eram presenciais.

Para resolver os problemas de uma pandemia, é preciso um esforço coletivo. É necessário adaptar-se de forma que os alunos não sejam prejudicados e que as aulas não fiquem paralisadas. Por consequência, surge uma questão de extrema relevância: como possibilitar o ensino e aprendizagem dentro de um cenário de pandemia mundial onde a palavra de ordem é isolamento social?

A intenção é apontar que as transformações ocorridas na sala de aula influem diretamente no interior da cultura escolar. Ademais, é preciso um esforço coletivo para resolver problemas. No contexto da pandemia, nota-se que há um esforço de educadores, pais e alunos no que diz respeito ao ensino e aprendizagem. É nesse instante que é preciso que os conceitos de aula, de sala de aula, de avaliação, dentre outros que estão diretamente implicados com os processos educativos, sejam reformulados e readaptados.

Enquanto se aguarda por uma solução para o isolamento social, seja por meio de remédios eficazes no combate ao vírus, seja com a descoberta de vacinas que imunizem as pessoas, a educação é o campo social e econômico que, mesmo afetado, não parou devido às imposições sem reflexões do ensino remoto. Para que isso seja possível, há um potencial nas tecnologias digitais móveis para proporcionar, mesmo que minimamente, a continuação dos processos educativos que poderiam sofrer prejuízos astronômicos caso a paralisação do ensino continuasse.

As TDMs como o smartphone, assim como o notebook, desempenham um papel fundamental nessa questão uma vez que, por meio de suas características de mobilidade 
DOI: https://doi.org/10.33238/ReBECEM.2020.v.4.n.3.24856

e ubiquidade, proporcionam, tanto ao professor quanto ao aluno, meios para não deixarem que seu trabalho e aprendizagem sejam totalmente paralisados.

Professores podem pensar atividades didáticas, gravar vídeos e enviá-los aos alunos por meio do dispositivo móvel, enquanto alunos que têm acesso a essa tecnologia podem receber textos, atividades, tarefas, enviar suas sistematizações e compreensões ao professor. Vê-se aqui a característica tanto de comunicação quanto a de facilitador do ensino e da aprendizagem. Segundo Chiari (2018, p. 362), “[...] assim, não podemos negligenciar as práticas de mídias anteriores, nem seu valor, mas precisamos lançar nosso olhar reflexivo sobre as novas possibilidades que as tecnologias digitais atuais trazem para a discussão $[\ldots .$. ”.

É preciso ainda fazer uma reflexão sobre as tecnologias. Quem tem acesso? Será que todos os professores e todos os alunos têm acesso a esses aparelhos? Será que todos têm uma internet de qualidade e um aparato tecnológico para que possam fazer os downloads e envio de atividades? Como fazer com que todos possam visualizar os vídeos propostos? São questões que precisam ser levantadas em meio à uma educação que está sendo imposta apenas para não atrasar calendários, a fim de dar continuidade ao processo educativo, e para que alunos não percam um ano de sua escolarização. Desse modo, o acesso de qualidade às TDMs, à internet e a uma formação e informação acerca de como utilizá-las ainda precisa ser discutido.

Mas e agora? Como fica o futuro? O que isso deixará como legado? Uma coisa é certa: nunca havia sido cogitado que isso seria um acontecimento que mudaria tão radicalmente a forma de ver a educação em tão pouco tempo. Ninguém estava preparado. Entretanto, foi necessária uma rápida reformulação para uma situação que modificou as relações pessoais e de ensino e aprendizagem.

\section{Reflexões finais}

É fato que a vida dos professores, dos alunos, pais e de outras pessoas envolvidas no processo educacional foram modificadas radicalmente com um cenário caótico que impulsionou todos a movimentar estruturas previamente definidas, como é o caso da aula presencial.

Professores precisaram movimentar-se em busca de informações e de soluções para continuar suas aulas, mas agora à distância. Alunos acostumados com aulas presenciais foram desafiados a aprender em casa, com ajuda de pais e responsáveis que 
DOI: https://doi.org/10.33238/ReBECEM.2020.v.4.n.3.24856

agora possuem mais responsabilidade para a educação de seus filhos. Não se sabe, todavia, como isso pode afetar suas aprendizagens.

O objetivo do ensaio era refletir quanto às possibilidades que as tecnologias digitais móveis trazem para a educação em tempos de pandemia e isolamento. Assim, as as TDMs trazem possibilidades como a ubiquidade, que configura um estudar em qualquer lugar - como a própria casa-, possibilitando ao professor pensar e planejar suas aulas de casa além de poder estabelecer um contato constante. Apesar das TDMs trazerem tudo o que foi comentado, foi a partir do esforço de cada um, professores e alunos, que o setor da educação não cessou o seu trabalho.

Ainda há, entretanto, outros campos a serem analisados, como o acesso de qualidade às TDMs e à internet por parte de alunos e professores, principalmente aqueles que estão situados em uma condição social menos favorecida e não possuem condições monetárias. Este assunto pode ser discutido com maior amplitude e reflexão em uma nova oportunidade de escrita.

No futuro, não se tem conhecimento de como as coisas continuarão, mas é sabido como estão atualmente: as águas da realidade estão turvas e obscurecidas. É preciso que haja apoio, tanto em relação à pandemia, quanto a educação, assim como também é preciso discutir os impactos que esse contexto caótico provocou aos processos educacionais.

Transformações ocorreram, as relações pessoais foram alteradas, quase que proibidas. É necessário, pois, um esforço coletivo para assegurar que as relações possam voltar a acontecer. As relações com as tecnologias digitais móveis também se alteraram e, a partir de agora, ver-se-á estas ferramentas como mais que essenciais para a educação, sendo aliadas em situações emergentes.

\section{Referências}

ALESSI, G. Itália pagou preço alto ao resistir a medidas de isolamento social para conter coronavírus. EL PAÍS, 25 de março de 2020. Disponível em:

$<$ https://brasil.elpais.com/internacional/2020-03-25/italia-pagou-preco-alto-ao-resistir-amedidas-de-isolamento-social-para-conter-coronavirus.html>. Acesso em: 05 mai. de 2020.

BAPTISTA, A. B.; FERNANDES, L. V. COVID-19, análise das estratégias de prevenção, cuidados e complicações sintomáticas. DESAFIOS - Revista Interdisciplinar Da

Universidade Federal Do Tocantins, v. 7, n. 3, p. 38-47, 2020. 
DOI: https://doi.org/10.33238/ReBECEM.2020.v.4.n.3.24856

BRASIL. Ministério da Saúde. Sobre a doença. Brasília, DF, 2020. Disponível em: <https://coronavirus.saude.gov.br/sobre-a-doenca>. Acesso em: 23 de julho de 2020. BORBA, M. DE C.; SCUCUGLIA, R. R. S.; GADANIDIS, G. Fases das tecnologias digitais em Educação Matemática: Sala de aula e internet em movimento. $1^{\mathrm{a}}$ ed. Belo Horizonte: Autêntica Editora, 2015.

CHIARI, A. S. de S. Tecnologias Digitais e Educação Matemática: relações possíveis, possibilidades futuras. Perspectivas da Educação Matemática, v. 11, n. 26, p. 351-364, 2018.

CONTI, T. V. Crise Tripla do Covid-19: um olhar econômico sobre políticas públicas de combate à pandemia. v. 1.1, 2020. Disponível em: < http://thomasvconti.com.br/wpcontent/uploads/2020/04/Conti-Thomas-V.-2020-04-06.-Crise-Tripla-do-Covid-19-olharecon\%C3\%B4mico-sobre-as-pol\%C3\%ADticas-p\%C3\%BAblicas-de-combate-\%C3\%A0pandemia.-Texto-para-discuss\%C3\%A3o.-Vers\%C3\%A3o-1.1.pdf>.

DISTRITO FEDERAL. DECRETO No 40.520, de 14 de março de 2020. Dispõe sobre as medidas para enfrentamento da emergência de saúde pública de importância internacional decorrente do novo coronavírus, e dá outras providências. Acesso em 27 de julho de 2020. Disponível em:

<http://www.sinj.df.gov.br/sinj/Norma/ed3d931f353d4503bd35b9b34fe747f2/Decreto_40520_1 4_03_2020.html>.

FIGUEIREDO, T. D. RODRIGUES, S. C. Professores e suas Tecnologias: uma cultura docente em ação. Educação em Revista, v. 36, 2020.

KESNKI, V. M. Tecnologias e Ensino Presencial e a Distância. $9^{\text {a }}$ ed. Campinas: Papirus, 2012.

MOREIRA, J. A. M.; HENRIQUES, S.; BARROS, D. Transitanto de um Ensino Remoto Emergencial para uma Educação Digital em Rede, em Tempos de Pandemia. Dialogia, n. 34, p. 351-364, 2020.

REZENDE, J. M. Epidemia, Endemia, Pandemia, Epidemiologia. Revista de Patologia Tropical, v. 27, n. 1, p. 153-155, 1998.

SANTAELlA, L. A Ecologia Pluralista da Comunicação: conectividade, mobilidade, ubiquidade. São Paulo: Paulus, 2010.

SANTAELLA, L. Comunicação Ubíqua: repercussões na cultura e na educação. $1^{\text {a }}$ ed. São Paulo: Paulus, 2013.

SÃO PAULO. DECRETO No 64.862, DE 13 DE MARÇO DE 2020. Dispõe sobre a adoção, no âmbito da Administração Pública direta e indireta, de medidas temporárias e emergenciais de prevenção de contágio pelo COVID-19 (Novo Coronavírus), bem como sobre recomendações 
DOI: https://doi.org/10.33238/ReBECEM.2020.v.4.n.3.24856

no setor privado estadual. Acesso em 27 de julho de 2020. Disponível em:

<https://www.al.sp.gov.br/repositorio/legislacao/decreto/2020/decreto-64862-13.03.2020.html>.

Recebido em: 7 de maio de 2020

Aceito em: 4 de agosto de 2020 